\title{
Rockfall travel distance analysis by using empirical models (Solà d'Andorra la Vella, Central Pyrenees)
}

\author{
R. Copons ${ }^{1}$, J. M. Vilaplana ${ }^{2}$, and R. Linares ${ }^{3}$ \\ ${ }^{1}$ Georisc S.L.P. C/Dr. Gimbernat, 2, baixos 3, 43205 Reus, Catalonia, Spain \\ ${ }^{2}$ Risknat Research Group, Geodynamics and Geophysics Department, University of Barcelona, C/Martí Franquès s.n., 08028 \\ Barcelona, Catalonia, Spain \\ ${ }^{3}$ Department of Geology (Geomorphology), Faculty of Science, Universitat Autònoma de Barcelona, 08193 Bellaterra \\ (Cerdanyola del Vallès), Catalonia, Spain
}

Received: 19 July 2005 - Revised: 24 September 2009 - Accepted: 4 November 2009 - Published: 14 December 2009

\begin{abstract}
The prediction of rockfall travel distance below a rock cliff is an indispensable activity in rockfall susceptibility, hazard and risk assessment. Although the size of the detached rock mass may differ considerably at each specific rock cliff, small rockfall $\left(<100 \mathrm{~m}^{3}\right)$ is the most frequent process. Empirical models may provide us with suitable information for predicting the travel distance of small rockfalls over an extensive area at a medium scale (1:1000001:25 000). "Solà d'Andorra la Vella" is a rocky slope located close to the town of Andorra la Vella, where the government has been documenting rockfalls since 1999. This documentation consists in mapping the release point and the individual fallen blocks immediately after the event. The documentation of historical rockfalls by morphological analysis, eye-witness accounts and historical images serve to increase available information. In total, data from twenty small rockfalls have been gathered which reveal an amount of a hundred individual fallen rock blocks. The data acquired has been used to check the reliability of the main empirical models widely adopted (reach and shadow angle models) and to analyse the influence of parameters which affecting the travel distance (rockfall size, height of fall along the rock cliff and volume of the individual fallen rock block). For predicting travel distances in maps with medium scales, a method has been proposed based on the "reach probability" concept. The accuracy of results has been tested from the line entailing the farthest fallen boulders which represents the maximum travel distance of past rockfalls. The paper concludes with a discussion of the application of both empirical models to other study areas.
\end{abstract}

Correspondence to: R. Copons

(ramon.copons@georisc.cat)

\section{Introduction}

Rockfall is a slope process in which a rock mass detaches from a steep face of a rock cliff and descends extremely fast by falling and subsequently rolling, sliding and finally stopping (Varnes, 1978; Hutchinson, 1988; Cruden and Varnes, 1996). Rock mass breaks up when impacting on the ground during its descent. This breaking up produces individual rock blocks, or fragmental blocks, which move independently when the size of the detached rock mass is roughly less than $10^{5} \mathrm{~m}^{3}$ (Evans and Hungr, 1993).

Usually, sizes of detached rock mass range significantly in a rock cliff depending on the abundance and characteristics of discontinuities (Rouiller et al., 1998; Dussuage-Peisser et al., 2002). Statistical analysis in database obtained in different study areas reveals a heavy-tailed behaviour for the frequency-size distribution (Dussuage-Peisser et al., 2002; Brunetti et al., 2009). Therefore, small rockfall $\left(<100 \mathrm{~m}^{3}\right)$ is the most frequent process in rockcliffs and is of particular interest for hazard analysis and risk management, since such events could occurs on a span of time from years to decades.

A necessary step for rockfall hazard analysis is the delimitation of the exposed area located below rock cliffs. Elements at risk (i.e. urban areas, infrastructures, recreational areas, etc.) are usually located below rock cliffs but not on the same rock outcrop, therefore it is essential to establish accurately the maximum rockfall travel distance. The lower boundary can be established by a geomorphologic approach entailing the farthest fallen boulders from previous rockfalls (Copons, 2007; Copons and Vilaplana, 2008; Wieczorek et al., 2008) or forecasting maximum travel distance for future rockfalls using heuristic, empirical or numerical models.

Published by Copernicus Publications on behalf of the European Geosciences Union. 
Several parameters (i.e. rockfall size, terrain elasticity and roughness, etc.) involve the post-failure dynamic of rockfalls and contribute to travel distance. The type of model to be applied for predicting travel distances will be chosen according to the extension of the study area, the mapping scale, the final purpose of the results and the available resources. For areas of limited extent, the modern approach is to use computer codes applying these parameters numerically. Numerical methods provide dynamic and cinematic results along the rock block trajectories which are necessary to design protective measures. Results have to be verified from past events included in a rockfall database. However, the practicality of adopting numerical models undertaking extensive mapping (thousands of $\mathrm{km}^{2}$ ) at medium scale (from 1:100000 to 1:25000 according to Fell et al., 2008) could be uncertain because this demands intensive resources. In this case, empirical models, or statistical models (Soeters and Van Westen, 1996), are easier to predict travel distances despite rough results should be expected. Empirical models also require the preparation of a database to be used by the statistical analysis (Corominas, 1996; Finlay et al., 1999; Martin, 2008). There are two main basic empirical models widely adopted: the reach angle (Heim, 1932) and the shadow angle (Lied, 1977; Evans and Hungr, 1993); nevertheless, empirical functions or values for predicting small rockfall travel distances differ considerably.

The purpose of this paper is (i) to propose a method to predict travel distance of small rockfalls $\left(<100 \mathrm{~m}^{3}\right)$ by using basic empirical models (both reach and shadow angle models), (ii) to verify empirical results obtained, and (iii) to discuss the use of these results for other study areas. For accomplishing these purposes, a high quality database has been prepared in the study area of "Solà d'Andorra la Vella" (Andorra, Central Pyrenees) (henceforth Solà d'Andorra) (Figs. 1 and 2) where the government is documenting rockfalls as soon as they occur (Copons et al., 2005; Copons, 2007). The data acquired has been used for analyzing the possible presence of parameters influencing rockfall travel distance, which is indispensable for checking the accuracy of the data acquired and the limitations of the empirical results.

\section{Main empirical statistical models: reach angle and shadow angle}

An empirical model is based on data acquired in a study area which is analysed by statistical methods. Results can be a function, or a single value, that can then predict rockfall travel distances in the same study area, or at another site with similar conditions (Soeters and Van Westen, 1996). However, this does not attempt to explain rockfall behaviour during the runout. If we assume that rockfall size and slope characteristics are constant over time, empirical models can predict the travel distance of future rockfalls from the data obtained of past events (Ayala-Carcedo et al., 2003). Empirical models are based on simplified assumptions in rockfall scenarios and therefore have a margin of error that can be assumed and accepted in a work undertaken on an extensive area at a medium scale.

In the literature, there are two main basic empirical models widely adopted for analysing the travel distance of rockfalls based on geometrical approaches: the reach angle (Heim, 1932; Shreve, 1968; Scheidegger, 1973; Hsü, 1975; Corominas, 1996) and the shadow angle (Lied, 1977; Evans and Hungr, 1993).

\subsection{Reach angle model}

Shreve (1968), Scheidegger (1973), and Hsü (1975) suggested the mobility index $H / L$, where $H$ is the fall height and $L$ is the horizontal length of the landslide (Fig. 3). The $H / L$ ratio is equivalent to the arctangent of the dipping of the line connecting the rockfall source (scar) to the distal fallen rock block of a rockfall. This dip is known by several names: "Fahrböschung" angle (Heim, 1932), travel angle (Cruden and Varnes, 1996), reach angle (Corominas, 1996) and travel distance angle (Hunter and Fell, 2003) amongst others.

The interpretation of the reach angle (A in Fig. 3) is based on an energy line applied from the top of the rockfall source and dipping downslope. The rock block released from the rock cliff will travel downslope with a kinetic energy equivalent to the height between slope surface and the energy line (Vaunat and Leroueil, 2002; Jaboyedoff and Labiouse, 2003). The rock block stops at the intersection point of the energy line with the topography where the energy has a value of 0. Shreve (1968) and Scheidegger (1973) considered that the tangent of the reach angle is equivalent to the coefficient of friction of the ground surface where the rockfall slides. This tangent is the relationship between the vertical drop $(H)$ and the horizontal component of the travel distance $(L)$ (Fig. 3). In this relationship, the longer the travel distance is, the lower the reach angle value will be $(\arctan H / L)$.

The reach angle method are widely adopted for rock avalanches (Scheidegger, 1973; Hsü, 1975; Erismann and Abele, 2001), rockfalls (Corominas, 1996; Petje et al., 2005), debris flows (Rickenmann, 1999), large landslides (Legros, 2002) and small landslides in artificial slopes (Finlay et al., 1999).

\subsection{Shadow angle model}

The shadow angle (B in Fig. 3) is the dipping of the energy line which connects the farthest fallen boulder to the apex of the talus slope (Lied, 1977; Evans and Hungr., 1993). Geometrically, the shadow angle is the arctangent of the relationship $H t / L t$ (Fig. 3), where $H t$ is the height of fall on the talus slope (elevation difference between the apex of talus slope and the farthest individual rock blocks of a rockfall) and $L t$ is the travel distance on the talus slope (horizontal distance between the apex of talus slope and the farthest individual rock block of a rockfall). 


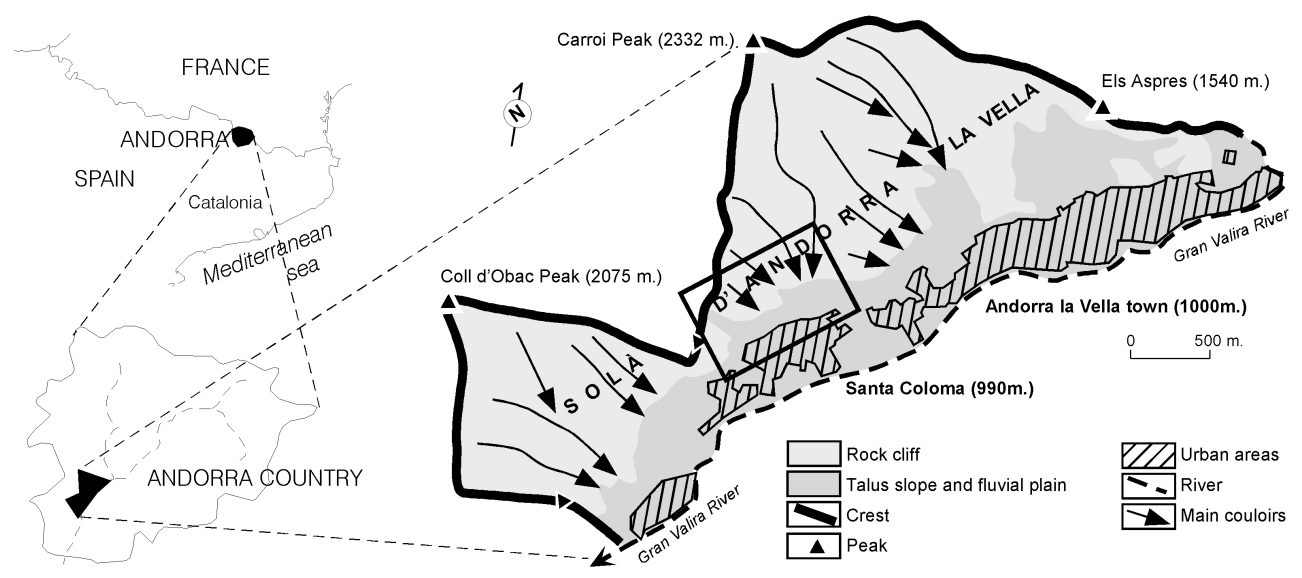

Fig. 1. Location maps of the Solà d'Andorra slope and sketch of the study area. The rectangle indicates the location of Fig. 12.

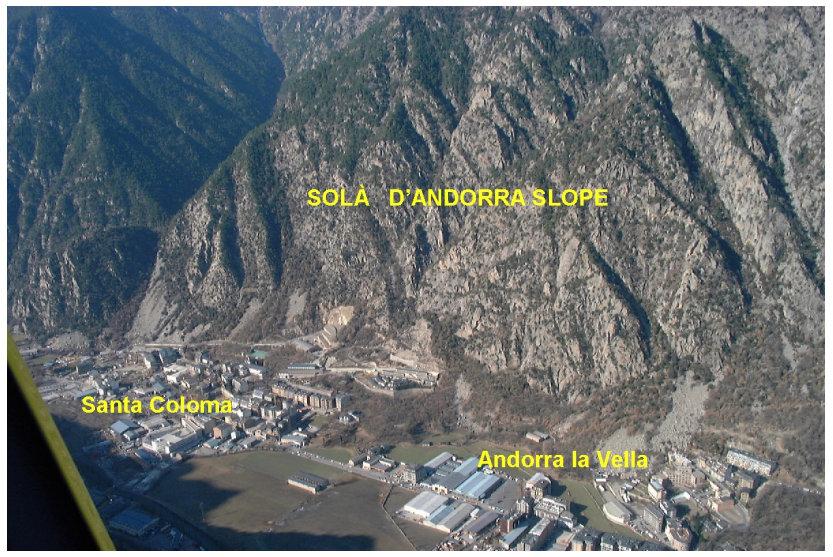

Fig. 2. View of a part of the Solà d'Andorra slope near of the outskirts of Andorra la Vella town and the Santa Coloma neighborhood.

Evans and Hungr (1993) considered that the kinetic energy acquired by rock blocks during their fall along the rock cliff is largely lost in the first impacts on the talus slope. The subsequent travel distance along the talus slope depends on the horizontal and rotational momentum acquired over this inclined talus slope. In this case, the energy line has to be applied at the top of the talus slope and the dip of the energy line would be the rolling friction angle for large boulder over a fine talus. This assumption could be only certain for rockfalls smaller than $10^{5} \mathrm{~m}^{3}$ where individual rock blocks fall independently.

The application of shadow angle does not require identifying the release and stopping point for each rockfall event but needs to identify the farthest boulders fallen in the past. The term of "minimum shadow angle" defines the lowest shadow angle assessed in a study area which usually corresponds to the farthest fallen boulder. Several values of minimum shadow angle are suggested in the literature: Lied (1977) proposed that values can range from $28^{\circ}$ to $30^{\circ}$;

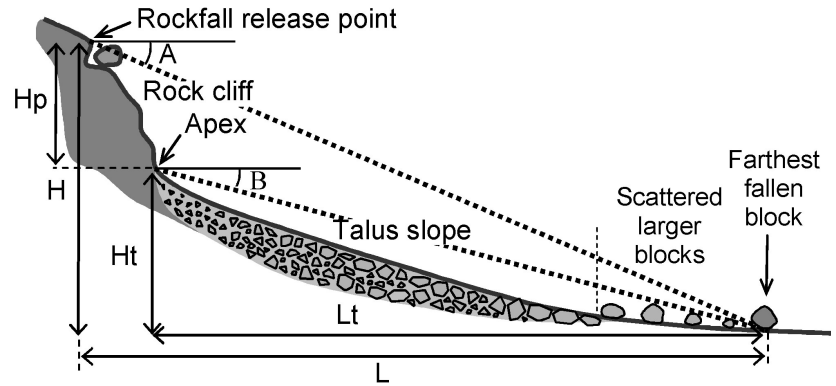

Fig. 3. Sketch of a cut slope which illustrates the rock cliff and the talus slope. Definitions of parameters explained on the text. (A: reach angle, B: shadow angle). Sketch modified from Evans and Hungr (1993) and Wieczorek et al. (2008).

Evans and Hungr (1993) established a value of $27.5^{\circ}$ by analyzing sixteen rockfall paths in British Columbia; Wieczorek et al. $(1998,2008)$ reported a mean value of $26^{\circ}$ from 25 boulders in Yosemite Valley and proposed a minimum shadow angle of $22^{\circ}$ for larger rockfalls; Meiß1 (2001) established a value of $31.5^{\circ}$ in German and Austrian Alps; and Copons (2004) found a farthest boulder with a minimum shadow angle of $25.5^{\circ}$, although more usual values range around $27^{\circ}$ in the Solà d'Andorra slope. Under atypical conditions, such as a glacial surface or smooth slope covered by grass or snow, the minimum shadow angle could be lower: Evans and Hungr (1993) found a small boulder with a value of $24^{\circ}$ over a smooth glacier; Domaas (1994) observed smallest angles, as low as $17^{\circ}$, in Norway; and Holm and Jakob (2009) observed a minimum shadow angle of $21^{\circ}$ under talus slope with fine debris in the Chilean Andes and suggested that minimum shadow angle values are not transferable to different rockfall areas with diverse debris lithologies. 


\section{The study area and the rockfall database}

The data used to support the analysis undertaken in this work has been acquired from both the documentation of recent rockfalls and the inventory of historical events at Solà d'Andorra.

\subsection{The Solà d'Andorra study area}

Solà d'Andorra is a steep rock cliff located in a glacially carved valley in the country of Andorra (Figs. 1 and 2). "Solà" is a Catalan term that defines a high and sunny slope facing south. The rock cliff exceeds $2000 \mathrm{~m}$ a.s.l., has a height of $1200 \mathrm{~m}$, covers an area of around $5 \mathrm{~km}^{2}$, and has a length of approximately $7.5 \mathrm{~km}$. Rockfall is one of the most dangerous phenomena. At the foot of the slope there are extensive talus slope generated by rockfall dynamics. In talus slope, rock blocks display considerable volumes (from 0.01 to $100 \mathrm{~m}^{3}$ ). Coarser boulders are located at the base of the talus slope. Beyond the base of talus slope, largest boulders are scattered over the fluvial plain.

The rock cliff contains a great amount of rockfall scars. One thousand of such rockfalls scars have been identified over a rock cliff surface of nearly $5 \mathrm{~km}^{2}$. The most frequent size is smaller than $100 \mathrm{~m}^{3}$ (almost 90\%). Some large rockfalls, which have about several thousands of cubic metres, and one rock avalanche have been identified (Copons, 2004).

Andorra la Vella, the capital of Andorra, is located close to Solà of Andorra and several rockfalls have damaged a number of buildings in recent years and infrastructures (Fig. 4). This prompted the Andorran Government to implement actions in order to mitigate the risk (hazard zoning and regulations, protective structures, etc.) (Copons et al., 2005). One of these has been to document the recent rockfalls by means of the Rockfall Surveillance Plan (Copons et al., 2005).

\subsection{Rockfall documentation}

Rockfall documentation consists in mapping on a 1:1000 scale map (Fig. 5) the main rockfall characteristics immediately after the event such as scar, rockfall trajectories and individual fallen rock blocks (position, volume, etc.). The size of the detached rock mass was determined in different ways: (i) measuring the dimensions of the scar if it is accessible, (ii) adding the volumes of all individual fallen rock blocks, and (iii) comparing the dimensions of the scar to the nearest trees. Trajectories of rockfall are reconstructed from the damaged vegetation and from impacts on the ground. Individual blocks are identified because of the freshly-broken surfaces and their volumes are measured.

From 1999 to 2008, approximately twenty rockfalls were documented in Solà d'Andorra. Fourteen rockfalls are selected for the empirical analysis undertaken in this work (see Table 1). Some of the documented rockfalls have been

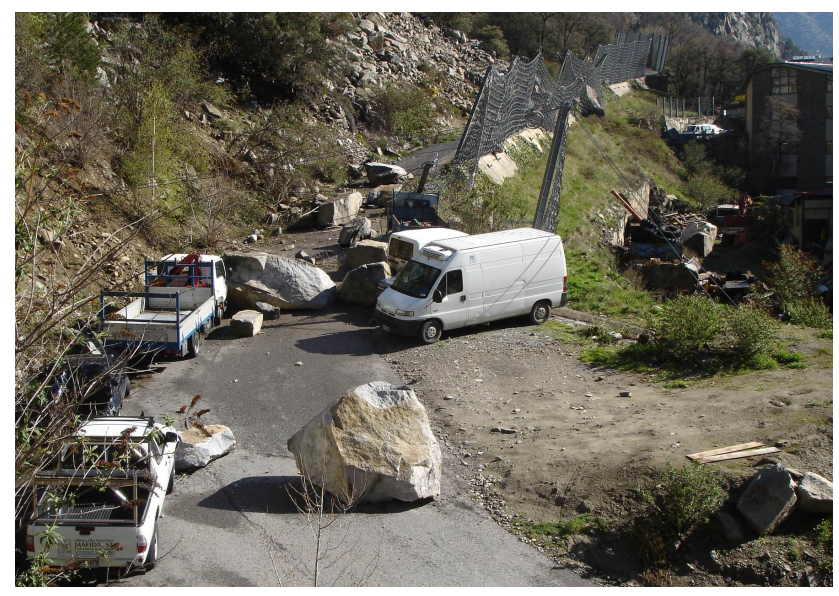

Fig. 4. Individual fallen rock blocks from the rockfall occurred on 20 April 2008.

rejected because their volumes are too small (smaller than $1 \mathrm{~m}^{3}$ ) or their information is not complete.

Rockfall sizes range from 5 to $150 \mathrm{~m}^{3}$, although one of the rockfall has a size of $300 \mathrm{~m}^{3}$; rock masses have been fragmented in an average of ten individual rock blocks; the volume of individual fallen blocks ranges from 0.1 to $14 \mathrm{~m}^{3}$; and travel distances range from 60 to $440 \mathrm{~m}$.

\subsection{Historical rockfall inventory}

The historical rockfall inventory is a record of older events obtained from eye-witness accounts, historical documents, old photographs and newspapers. Rockfalls have basically been mapped by means morphologic observations.

An amount of twenty one events have been inventoried (Copons, 2004): twelve rockfalls over the 1950-1980 period and nine rockfalls over the 1981-1998 period. Despite the considerable amount of events recorded, only the release and stop point of six of these events have been identified (see Table 1): two of them over the 1950-1980 period, and four over the 1981-1998 period.

\section{Empirical analysis of the parameters influencing on travel distances}

The practicality of both empirical models, reach and shadow angles, has been checked by means of the relationships between simple topographical variables considered, vertical height and horizontal length, by using the data acquired at Solà d'Andorra. The plot of the total height $(H)$ versus the length of travel distance $(L)$ in Fig. 6a, which represents the reach angle, shows a linear regression equation fitted with a squared correlation of 0.995 . Figure $6 \mathrm{~b}$ shows the plot between parameters used by the shadow angle concept: height on talus $(H t)$ and travel distance on talus $(L t)$. The regression equation fitted gives a squared correlation of 0.993 . 


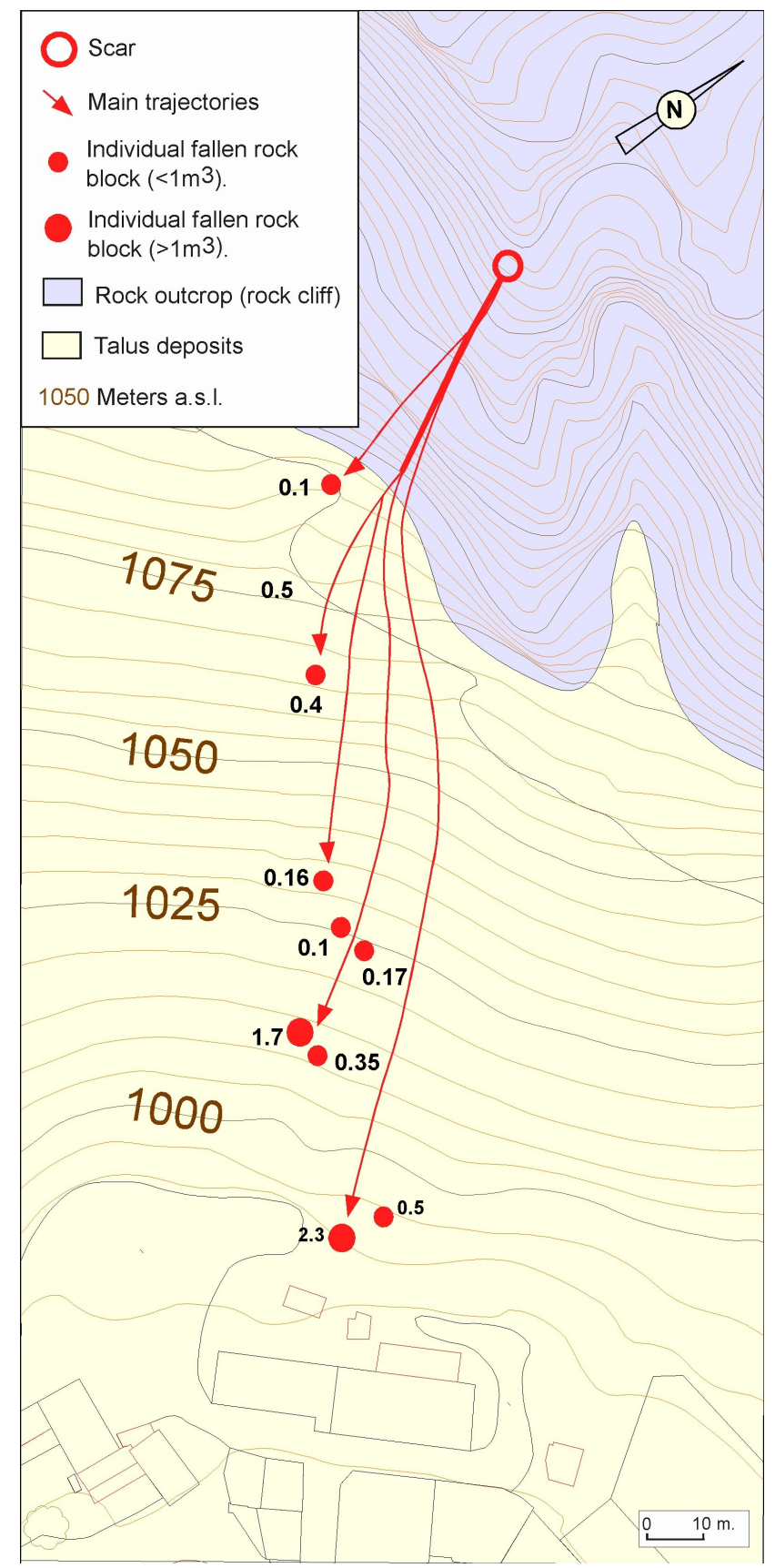

Fig. 5. Map of the rockfall occurred in August 2003. Numbers listed for each individual fallen rock block are volumes in $\mathrm{m}^{3}$. Map simplified from the technical report undertaken by the Andorran Government in the framework of Rockfall Surveillance Plan.

The strong relationship between variables and their linear trends may suggest the reliability of empirical angles for predicting travel distances whatever the length of travel distances. Dispersion of values with linear regression fitted may be due to non-homogeneous conditions of both rockfall and terrain characteristics which may have an influence on travel distances.
Table 1. Summarized rockfall database at Solà d'Andorra. The first fourteen events are obtained from the rockfall documentation by the Surveillance Plan. The last six events are obtained from the historical rockfall inventory.

\begin{tabular}{|c|c|c|c|c|c|c|}
\hline \multirow[t]{2}{*}{$\begin{array}{c}\text { Rockfall } \\
\text { event } \\
\text { date }\end{array}$} & \multirow{2}{*}{$\begin{array}{c}\text { Rockfall } \\
\text { size } \\
\left(\mathrm{m}^{3}\right)\end{array}$} & \multicolumn{2}{|c|}{$\begin{array}{c}\text { Reach } \\
\text { angle of } \\
\text { individual } \\
\text { rock blocks }\end{array}$} & \multicolumn{2}{|c|}{$\begin{array}{c}\text { Shadow } \\
\text { angle of } \\
\text { individual } \\
\text { rock blocks }\end{array}$} & \multirow{2}{*}{$\begin{array}{l}H p \\
\\
\text { (m) }\end{array}$} \\
\hline & & Min. & Max. & Min. & Max. & \\
\hline 1 Jan 1999 & 20 & 0.82 & 1 & 0.64 & 0.72 & 95 \\
\hline 4 Apr 1999 & 5 & 1.02 & 1.25 & 0.78 & 0.86 & 100 \\
\hline 17 Apr 2000 & 5 & 0.93 & 1.3 & 0.68 & 0.71 & 82 \\
\hline 11 May 2000 & 5 & 1.08 & 1.08 & 0.69 & 0.69 & 72 \\
\hline 14 Jun 2000 & 30 & 0.9 & 0.85 & - & - & 102 \\
\hline 23 Nov 2000 & 10 & 0.89 & 1.01 & 0.65 & 0.7 & 124 \\
\hline 16 May 2001 & 10 & 0.93 & 1.16 & 0.67 & 0.89 & 255 \\
\hline Nov 2001 & 5 & 0.88 & 1 & 0.67 & 0.75 & 15 \\
\hline Nov 2002 & 10 & 0.92 & 1.41 & 0.66 & 0.77 & 60 \\
\hline 24 Nov 2002 & 30 & 0.94 & 1.34 & 0.58 & 0.69 & 118 \\
\hline Feb 2003 & 300 & 0.81 & 0.9 & 0.62 & 0.78 & 33 \\
\hline 17 Aug 2003 & 10 & 1.02 & 1.76 & 0.67 & 0.83 & 98 \\
\hline 2 Apr 2004 & 25 & 0.86 & 1.06 & 0.69 & 0.74 & 70 \\
\hline 20 Apr 2008 & 150 & 0.87 & 1.12 & 0.61 & 0.71 & 90 \\
\hline 21 Jan 1997 & 60 & - & 0.82 & - & 0.7 & 60 \\
\hline 1994 & - & - & 1.24 & - & 0.63 & - \\
\hline 11 Jan 1996 & - & - & 0.92 & - & 0.78 & - \\
\hline 25 Dec 1983 & - & - & 0.85 & - & 0.7 & - \\
\hline 1960’s & - & - & 0.81 & - & 0.72 & - \\
\hline 1970's & 150 & - & 0.79 & - & 0.6 & 120 \\
\hline
\end{tabular}

Several parameters can influence on rockfall travel distance: size of the released rock mass (Corominas, 1996; Okura et al., 2000; Erismann and Abele, 2001), slope characteristics (Corominas et al., 1990; Krummenacher and Keusen, 1997), individual rock block volumes (since the coarsest boulders are located at the base of the talus slope), vegetation (Dorren, 2003) and morphologic constraints of the path (Nicoletti and Sorriso-Valvo, 1991; Corominas, 1996).

It is well know that the reach angle value of large rockfalls strongly depends on the detachment size $(M)$ (Scheidegger, 1973; Corominas, 1996; Erismann and Abele, 2001). So, the larger the size of the rockfalls, the smaller is the reach angle value. Rockfall experiments with discrete rock bodies also reveal that size contributes to larger travel distance (Okura et al., 2000). Corominas (1996) established a logarithmic relationship between rockfall volume and the tangent of the reach angle $(H / L)$ for rockfalls on a range of $10^{2}-10^{8} \mathrm{~m}^{3}$. Data gathered in Andorra, plotted in Fig. 7a and b, also shows a clear relationship between sizes of small rockfalls and travel distances, although the data represented is rather scattered. Two hypothesis may be suggested from the dependency of tangent of shadow angle on rockfall size showed in Fig. 7b: (i) the rockfall size influences on the horizontal momentum of kinetic energy probably by the sliding of released rock 

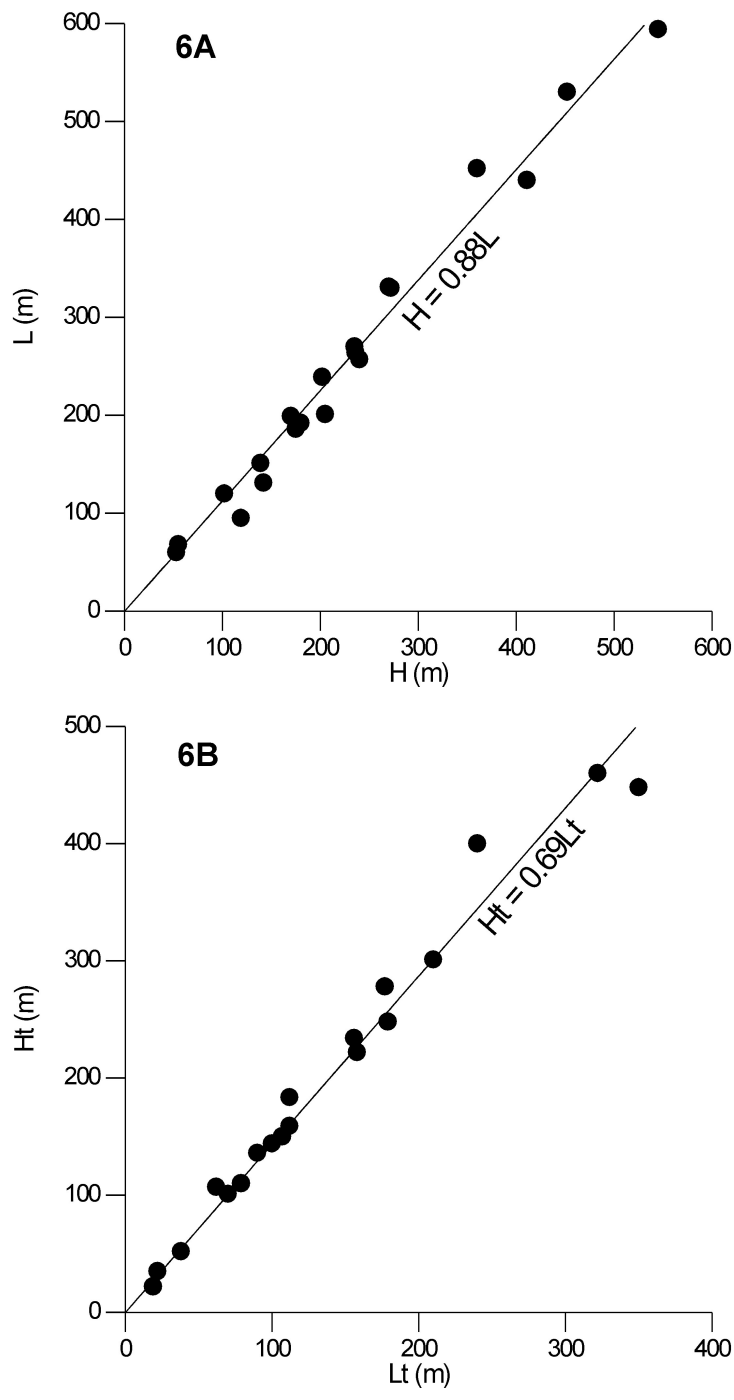

Fig. 6. (A) Plot of total travel distance $(L)$ versus total height $(H)$ with fitted regression line. The correlation coefficient is 0.995 . (B) Plot of travel distance on talus slope $(L t)$ versus height on talus slope $(H t)$ with fitted regression line. The correlation coefficient is 0.993 .

mass over faces of unstable joints, and (ii) the kinetic energy acquired on the initial release is not totally lost in first impacts on talus slopes. Figure 8 represents the plot of a more wide range of rockfall sizes $(M)$ considering data gathered from several authors. The equation fitted at Fig. 8 follows a logarithmic trend without sudden changes and its coefficient correlation is stronger that the coefficient found when considering only small rockfalls (Fig. 7a). Therefore, the effect of rockfall size on travel distance is strong and continuous, despite the fact that small rockfalls $\left(<10^{5} \mathrm{~m}^{3}\right)$ have a different dynamic of motion than the larger ones $\left(>10^{6} \mathrm{~m}^{3}\right)$ (Erismann and Abele, 2001). Although the correlation coefficient of 0.764 is rather strong, the high scattering of data suggests the presence of other parameters which influence rockfall travel distances.
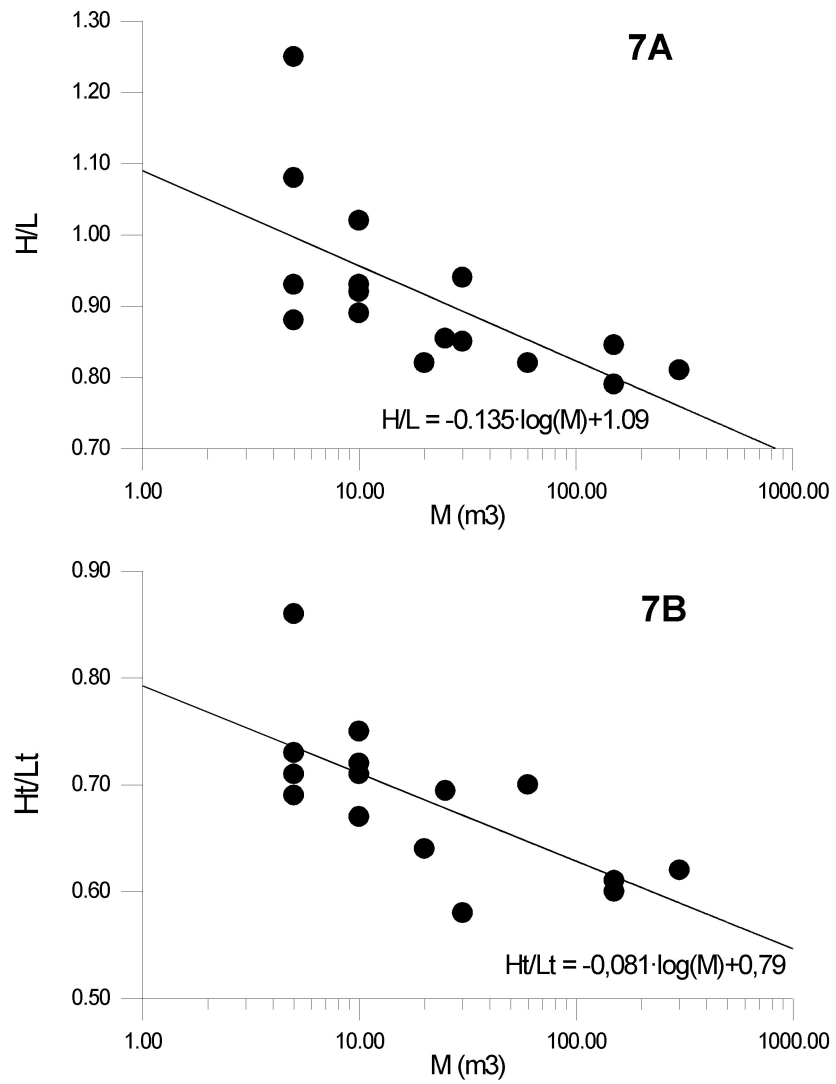

Fig. 7. Plots of rockfall size $(M)$ versus: (A) tangent of reach angle $(H / L)$, and (B) tangent of shadow angle $(H t / L t)$ with fitted regressions lines which evidence the tendency of data. Values of correlation coefficient are around 0.5 .

The effect of the height of fall ( $\mathrm{Hp}$ parameter in Fig. 3) along the rock cliff has been analysed in Fig. 9a and b. Taking into account that rockfall size influences on travel distances, plots in Fig. 9 represent four sets of volume ranges $\left(0-9,10-49,40-99\right.$, and $\left.100-300 \mathrm{~m}^{3}\right)$. Scatter plots show a very weak relationship between the $H p$ parameter and the travel distance considering both individual and grouped sets of volumes ranges. This proves that the kinetic energy acquired along the rock cliff is largely lost at the top of talus slope (Evans and Hungr, 1993) but perhaps not totally.

No relationship has been obtained plotting individual rock block volumes $(V)$ and the tangent of reach angle (Fig. 10a). The scatter of Fig. 10b plots the rock block volumes and the travel distance by means of the shadow angle. Data has been added from the farthest boulders found at the study area, since they represent the largest volumes and largest travel distances from past rockfalls. All data plotted has a high degree of scattering, but a negative relationship has been observed (Fig. 10b) between block volume and $H t / L t$ ratio value. A regression equation has been fitted by the lower envelope of plotted data which estimate the maximum travel distance of rock blocks by taking into account their volume. 


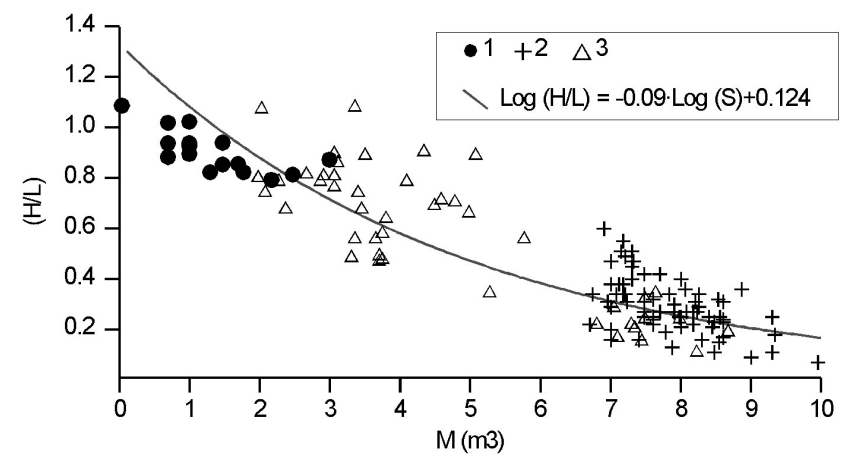

Fig. 8. Plot of rockfall size $(M)$ versus tangent of the reach angle $(H / L)$ considering data gathered from different authors. The line represents the fitted regression line with a correlation coefficient of 0.764. Key to numbers: (1) data by Copons (2004), (2) data by Erismann and Abele (2001), and (3) data by Corominas (1996).

This equation may be applied for rockfalls with the same size than the documented rockfalls (from 5 to $150 \mathrm{~m}^{3}$ ).

Nicoletti and Sorriso-Valvo (1991) considered three types of morphologic constrains along the rock avalanche paths: (i) channeling of the detached mass, (ii) unobstructed spreading of the detached mass, and (iii) right-angle impact against an opposite slope. Corominas (1996) analysed these morphologic constraints in several landslides processes and found a strong influence on reach angle values. The trajectories of rockfalls documented in Solà d'Andorra do not have significant obstruction and data gathered was not useful for analysing the influence of morphologic constrains on small rockfalls.

Slope characteristics could influence on travel distances especially for small rockfalls: slope roughness, ground elasticity and forest density (Corominas et al., 1990; Krummenacher and Keusen, 1997; Dorren, 2003). Several attributes can be considered for each slope characteristic. As an example, Krummenacher and Keusen (1997) considered four attributes related to the ground elasticity for numerical modeling: rock outcrop, thin soil, thick soil and screes. However, the amount of available data in Andorra together with the existing literature is not yet large enough for analyzing the influence of slope characteristics for travel distances.

\section{Predicting travel distances}

Taking into account the scattering on travel distances, as well as the reach and shadow angle approaches from the documented rockfalls, the travel distance has been predicted by adopting the "reach probability" concept (Rouiller et al., 1998). Reach probability is the frequency (expressed in terms of percentage or probability) of falling rock blocks that could reach a point of the exposed area located below a rock cliff. The "reach boundary" line is obtained by joining points with the same value of reach probability. Reach boundaries
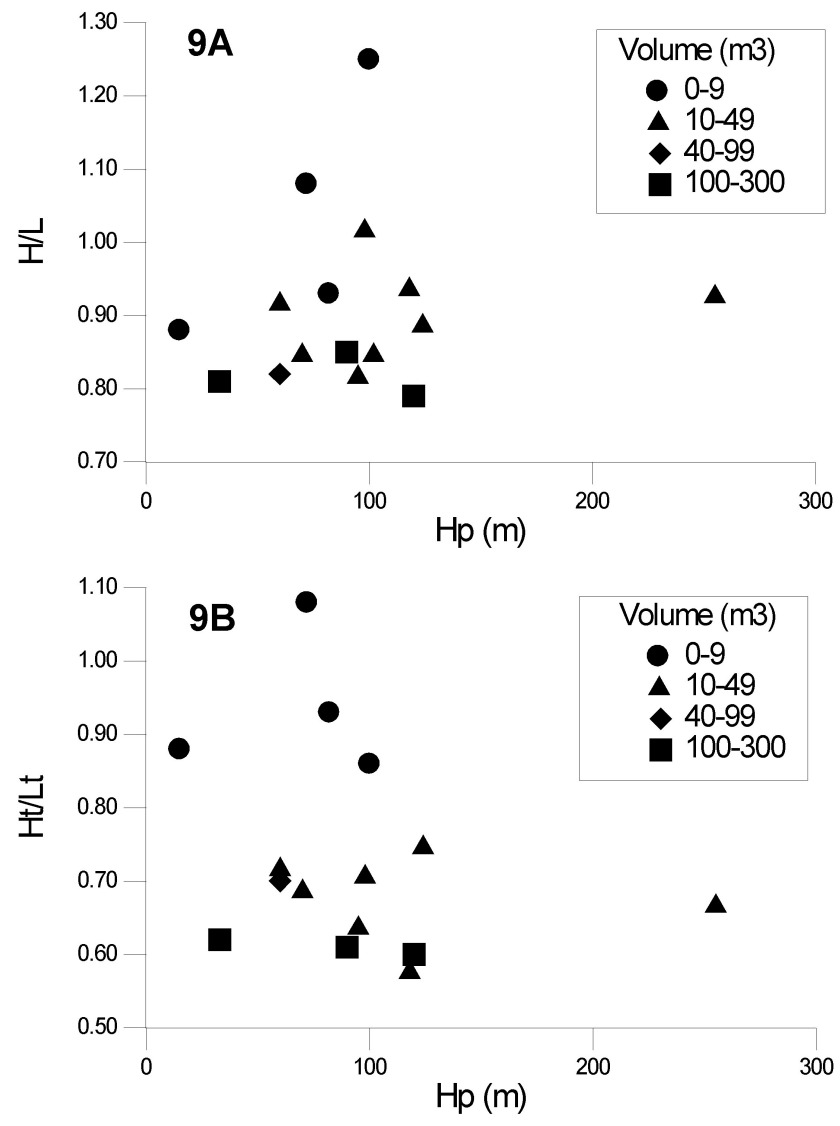

Fig. 9. Plots of the height of fall on the rock cliff $(\mathrm{Hp})$ versus: (A) tangent of reach angle $(H / L)$, and (B) tangent of shadow angle $(H t / L t)$. The scatter plot shows a very weak relationship between variables represented.

are a quantitative approach to travel distances useful for susceptibility and hazard assessments (Copons, 2007; Copons and Vilaplana, 2008).

Value of reach probability ranges from 0 to 1 . From this probabilistic approach, the closer a point of talus slope is from the rock cliff, the higher is the value of reach probability. Value 1 represents points where all individual rock blocks reached and usually located at the foot of the rock cliff. Any individual rock block may reach points with a value of 0 .

For predicting travel distances we have used the reach boundaries of $0.1,0.01$, and 0.001 which characterize the reach of $10 \%, 1 \%$, and $0.1 \%$ of the individual rock blocks, respectively. The last value, which is the lowest, may correspond roughly to the maximum travel distance of rockfalls.

\subsection{Empirical estimation of the reach probability}

A univarible statistical analysis from documented individual blocks has been used to obtain empirical angles for each reach boundary considered. This statistical analysis requires calculating the tangent of the reach and shadow angles for 

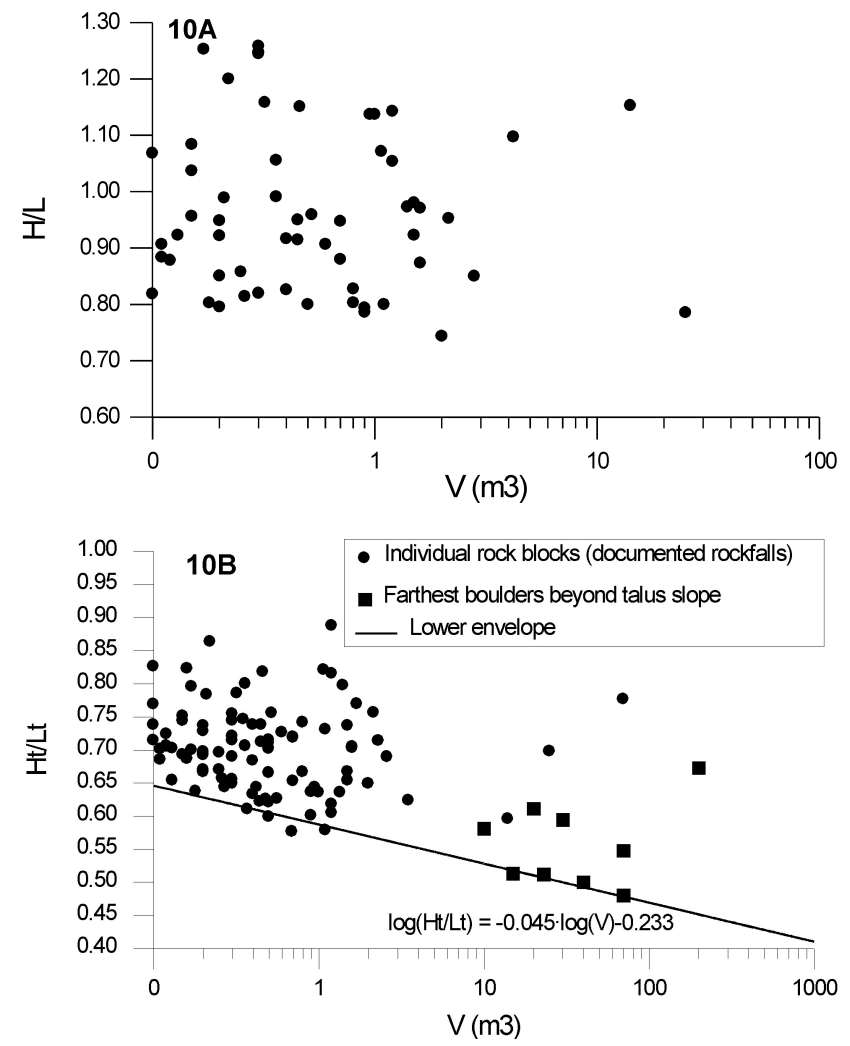

Fig. 10. Plots of individual rock blocks volumes $(V)$ versus: (A) tangent of reach angle $(H / L)$, and (B) tangent of shadow angle $(H t / L t)$. The fitted lower envelope in Fig. 10b has a correlation coefficient of 0.983 .

every individual documented rock block. All the data has been grouped for the calculation of percentile values. The 90th, 99th, and 99.9th percentile correspond to the percentage of blocks stopped before reaching the $0.1,0.01$, and 0.001 reach boundaries, respectively.

A total amount of 110 documented individual rock blocks have been used for the statistical analysis of the reach angle (Fig. 11a). Tangent of reach angle values range from 0.75 to 1.5 , with a mean value located at the $0.95-1$ interval. 90th, 99th, and 99.9th percentiles are located at $0.878\left(41.3^{\circ}\right)$, $0.824\left(39.5^{\circ}\right)$, and $0.751\left(36.9^{\circ}\right)$ values. Since the number of data is slightly higher than a hundred, the value of 99.9th percentile must be considerate as a rough estimation.

A total amount of 103 individual rock blocks are stopped on talus slopes. This data is used for the statistical analysis of shadow angle (Fig. 11b). Values range from 0.60 to 0.86 with a mean value located at the $0.70-0.75$ interval. 90 th and 99th percentiles are situated at $0.620\left(31.8^{\circ}\right)$, and $0.577\left(30^{\circ}\right)$ values. The available data is not enough to obtain a value for the 99.9th percentile. In this case, a shadow angle of $27^{\circ}$ has been used which represents the usual value of minimum shadow angles from the farthest boulders identified beyond the talus slope base.
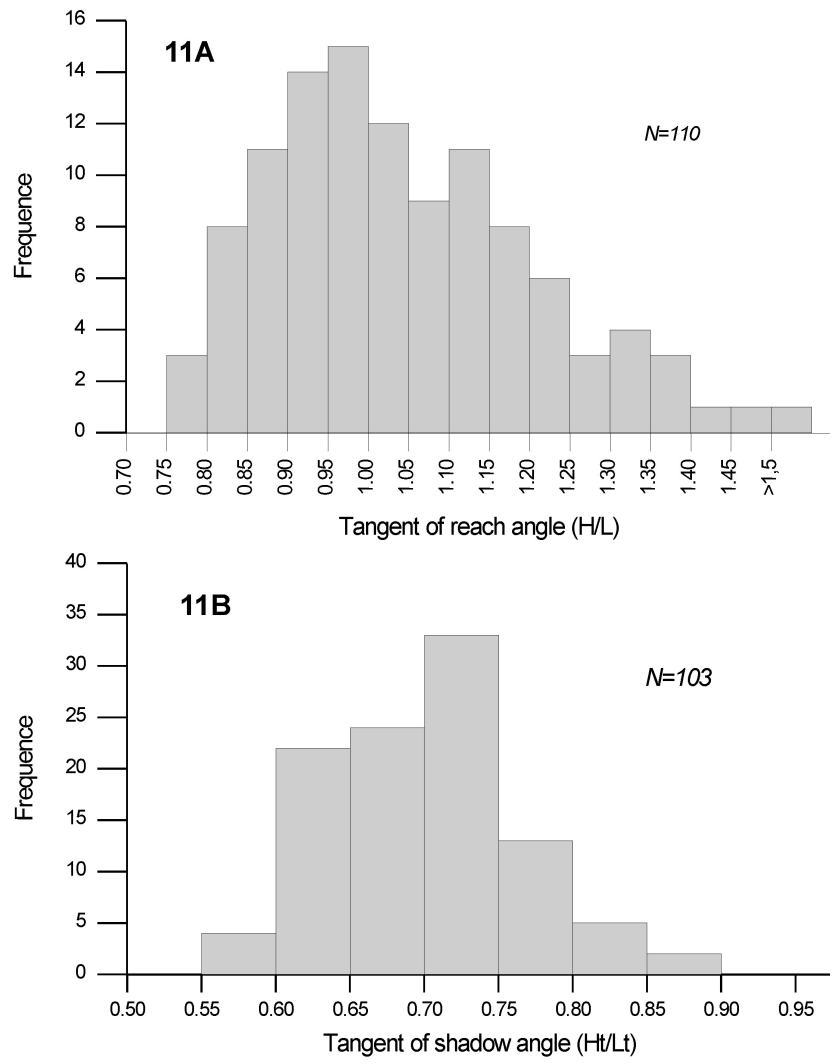

Fig. 11. Histograms of reach angle values (A) and shadow angle values (B) from individual fallen rock blocks documented at the Solà d'Andorra slope.

Since travel distance depends on rockfall size, these angle values are roughly appropriate for the rockfall sizes documented (from 5 to $150 \mathrm{~m}^{3}$ ). These values will predict quite optimistic travel distances for larger sizes and somewhat pessimistic for smaller ones. Nowadays, the amount of available data is insufficient to analyse travel distances in small intervals of volumes within the range considered.

\subsection{Mapping travel distance}

The prediction of travel distance using the reach angle concept requires identifying and mapping of potential rock slope failure.

For local scale mapping $(<1: 5000)$, a structural analysis, considering rock-mass-quality and joint characteristics, yields suitable results (Coe and Harp, 2007).

Medium scales usually cover large areas which make unfeasible the use of structural analysis. The geomorphologic analysis requires the mapping of all the potential sources, such as scars, detached rock blocks but not yet fallen, and open joints (Copons, 2004) which also demand large scale maps $(<1: 5000)$. At medium scales, an envelope entailing potential sources may be drawn. The upper envelope roughly coincides with the top of the rock cliff where have been keyed energy lines dipping $41.3^{\circ}, 39.5^{\circ}$, and $36.9^{\circ}$. This upper 

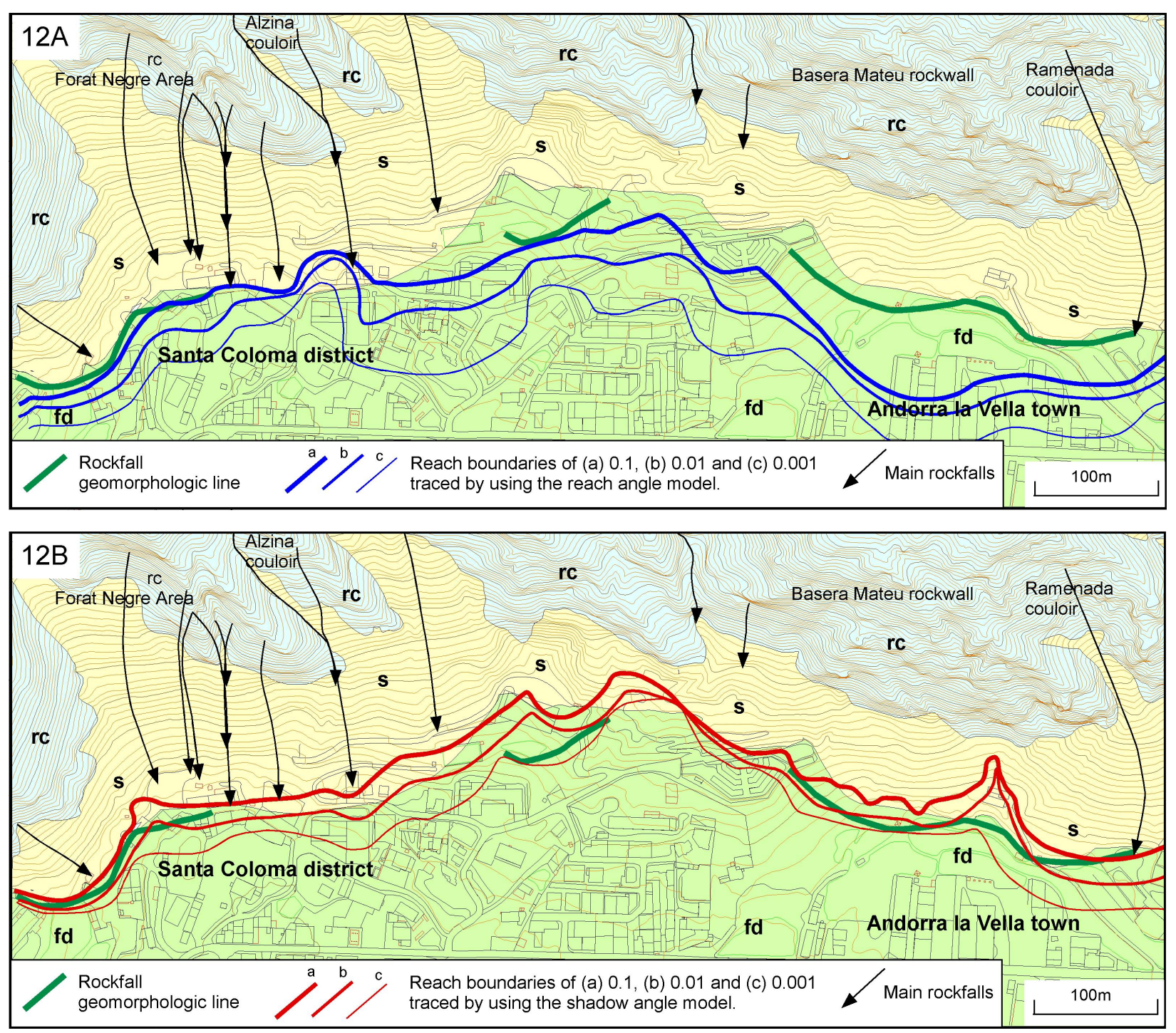

Fig. 12. Maps of travel distance by means reach probability boundaries, or limits, traced by both reach angle (A) and shadow angle models (B). Legend: (rc) rock cliff, (s) talus slope, (fd) fluvial and torrential deposits. See the location of this sketch at the Fig. 1.

envelope located on the top of rock cliff symbolises the "worst case scenario" of the empirical estimation since the predicted travel distances will be the longest (Fig. 3).

The application of the shadow angle is easier because energy lines of $31.8^{\circ}, 30^{\circ}$, and $27^{\circ}$ are simply traced from different talus apexes. Some parts of the apex that may be semieroded by torrential dynamics have been rejected for the application of energy lines.

Figure 12 shows reach probabilities of $0.1,0.01$, and 0.001 by using both reach (Fig. 12a) and shadow angle (Fig. 12b) concepts. When comparing both maps (Fig. 12a for reach angle and Fig. 12b for shadow angle approach), travel distances predicted by using reach angle are longer than those predicted by the shadow angle. Reach boundaries traced by using shadow angle rarely represent longer travel distance. On the one hand, reach boundaries traced by "shadow" are closer and located nearer the foot of the talus slope. On the other hand, reach boundaries traced by "reach" spread over the fluvial plain.

\subsection{Accuracy of reach boundaries predicted}

The "rockfall geomorphologic line" (Copons, 2004) is the line that entails both the farthest boulders and the foot of the talus slope. If it is assumed that the conditions influencing rockfall runout (such as rockfall size, individual rock block volumes, slope roughness and forest vegetation) are constant over the time, the geomorphologic line can be considered 
as the envelope of future rockfall maximum travel distances. Therefore, the geomorphologic line has been used to verify the accuracy of reach probability boundaries traced by both empirical models (reach and shadow angle).

Solà d'Andorra has similar characteristics to a typical rockfall scenario (Rapp, 1960; Evans and Hungr, 1993; Wieczorek et al., 2008): (i) an extensive talus slope located below the rock cliff, (ii) an area with the largest scattered boulders over a fluvial plain located beyond the base of the talus, and (iii) a fluvial plain without any geomorphologic evidence of rockfalls. However, part of the talus slope foot has been altered by old quarries and the outskirts of the "Andorra la Vella" town are settled in the area with the largest scattered boulders. So, development has erased a large part of the farthest rockfall deposits and only some sections of the rockfall geomorphologic line has been able to be drawn (Fig. 12).

None of the documented rockfalls crossed sections of the geomorphologic line. Reach boundaries traced by shadow angle are located close to the rockfall geomorphologic line, whereas reach boundaries traced by reach angle are located further and usually over the fluvial plain without rockfall evidences. Therefore, the reach angle model, applied on the top of a rock cliff, may predict an excessive travel distance, whereas the shadow angle model may be more suitable since it shows more acceptable results.

\subsection{Performance of empirical models}

The rockfall database at Solà d'Andorra yields high quality information for checking the use of empirical models used to predict the exposed area as well as providing empirical values for reach boundaries. However, the wide range of minimum shadow angle values existing in the literature (see Sect. 2.2) proves that the results obtained at Solà d'Andorra are not directly applicable to the overall rockfall scenarios as a general rule. It should be taken into account that Solà d'Andorra represents large screes with a mean "angle of repose" (Carson, 1977) of approximately $34^{\circ}$. For mature and stable talus slopes, the angle of repose ranges from $32^{\circ}$ to $36^{\circ}$ and the exact value will depend on slope conditions such as the size, shape and roughness of the debris (Goudie, 2004). Therefore, the location of the apex could be rather arbitrary in areas with talus slopes not matured enough; in these cases, shadow angle values obtained in this work cannot be directely transferable (Guzzetti el al., 2003).

In areas with immatured talus slopes, the appropriate task would be the preparation of a rockfall database. However, it is difficult to obtain sufficient number of cases for determining empirical values for reach boundaries as events must be recent enough to allow for the identification of both source and fallen rock blocks (Hungr et al., 2005). In this case, an absolute maximum travel distance for future rockfalls may be assessed by the minimum shadow angle approach from the recognition of farthest boulders over the terrain.
If the study area is devoid of talus slopes then the reach angle model is needed. In this case, a geomorphologic analysis of the rock cliff is required in order to identify potential rockfall sources and to determine potential rockfall sizes. The suitable angle of reach could be selected from regression equations fitted in Sect. 3 (Fig. 8). It should also be borne in mind that the small amount of data in the existing database as yet impedes us obtaining regression equations applicable as a rule for the overall slope characteristics. Therefore, it is necessary to consider a large oversimplification of these characteristics and to assume a certain error.

\section{Conclusions}

The travel distance of small rockfalls $\left(<100 \mathrm{~m}^{3}\right)$ has been analysed by using the main basic empirical models existing in the literature: reach and shadow angle models. The reason for adopting these models is that they are easier to handle in the application "energy lines" to predict travel distances despite their rough results. Hence, empirical models are suitable tools for predicting travel distances in extensive areas at medium scales (from 1:100 000 to 1:25000). However, the requirement of a consistent database, which includes a significant number of data indispensable for the statistical analysis, proves difficult to achieve the accurate use of empirical models.

Nevertheless, at Solà d'Andorra, a rockfall database with high quality information has been achieved by the continuous documentation of rockfall events and the inventory of historical rockfalls. Six historical rockfalls, which occurred between 1950 and 1998, and fourteen rockfall events documented since 1999, provide a sufficient amount of precise information for the empirical analysis and for proposing empirical values to predict travel distances.

A logarithmic regression is fitted from small rockfalls documented in Andorra and from those of larger rockfalls existing in the literature by using the reach angle model concept. This regression equation which covers a huge range of sizes, from 5 to $10^{8} \mathrm{~m}^{3}$, verifies a strong and constant influence of the detached rock mass size on travel distances. Moreover, the volume of individual rock blocks, which comes from the fragmentation of the detached rock mass, could have a secondary influence on travel distance. No relationship has been detected between the height of fall over the rock cliff and the travel distance. These results give evidence that the horizontal momentum of kinetic energy acquired in the first movement of the rockfall release may influence on the travel distance of individual fallen rock blocks. Nevertheless, the vertical momentum of kinetic energy acquired at the fall along the rock cliff is largely lost in the first impacts on talus slope.

Travel distance has been predicted by using the "reach probability" concept which is the frequency, expressed in terms of probability, of individual fallen rock blocks that could reach a point located below a rock cliff. The "reach 
boundary" line is obtained by joining points with the same value of reach probability. Reach probabilities of $0.1,0.01$, and 0.001 have been used for analyzing and mapping travel distances. Result of the basic statistical analysis achieved provides reach angles values of $41.3^{\circ}, 39.5^{\circ}$, and $36.9^{\circ}$, and shadow angles of $31.8^{\circ}, 30^{\circ}$, and $27^{\circ}$, to the $0.1,0.01$, and 0.001 reach probabilities, respectively. The adoption of the "reach probability" concept described in this paper represents advancement in the prediction of travel distances by using empirical models.

The line entailing the farthest boulders, here known as the "rockfall geomorphologic line", has been used to verify the accuracy of reach probability boundaries. The verification reveals that the shadow angle model yields results more suitable in our study area characterized by a mature talus slope. Results by using the reach angle approach, where energy lines are applied from the top of rock cliff, predicts excessive travel distance.

Empirical results obtained at Solà d'Andorra are not directly transferable to other rockfalls scenarios. In areas with mature talus slopes, the literature differs on the "minimum shadow angle" because slope characteristics strongly influence on travel distances. In areas where the talus slope is not mature enough, the location of the apex could be arbitrary and the prediction of travel distances by using unverified shadow angle values could be inaccurate. In areas without talus slopes, the reach angle approach is needed to predict travel distances and this requires identifying potential rockfall sources over the rock cliff and having suitable empirical values according to the local characteristics (expected rockfall sizes, forest vegetation, terrain roughness, ground elasticity and morphologic constrains). Further advances in the application of basic empirical models in large areas are necessary and will require the preparation of a consistent database made from studies undertaken of overall of rockfall scenarios.

Acknowledgements. The Andorran Ministry for Land Use and Public Works (Andorran Government) supported rockfall documentation undertaken at Solà d'Andorra. Authors gratefully acknowledge Euroconsult Andorra S.A. Company which nowadays is documenting rockfalls events. This research has been carried in the framework of the project SAXUM with reference number 2008ITT00004 (Work Community of the Pyrenees: Catalonia and Andorra). We are grateful to Thomas Glade for his helpful and editorial handling. Comments from anonymous reviewers helped to improve the original manuscript.

Edited by: T. Glade

Reviewed by: two anonymous referees

\section{References}

Ayala-Carcedo, F.J., Cubillo-Nielsen, S., Alvarez, A., Domínguez, M., Laín, L., Laín, R., and Ortiz, G.: Large Scale Rockfall Reach Susceptibility Maps in La Cabrera Sierra (Madrid) performed with GIS and Dynamic Analysis at 1:5000, Nat. Hazards, 30(3), 325-340, 2003.

Brunetti, M. T., Guzzetti, F., and Rossi, M.: Probability distributions of landslide volumes, Nonlin. Processes Geophys., 16, 179-188, 2009, http://www.nonlin-processes-geophys.net/16/179/2009/.

Carson, M. A.: Angles of repose, angles of shearing resistance and angles of talus slopes, Earth Surf. Proc. Land., 4(2), 363-380, 1977.

Coe, J. A. and Harp, E. L.: Influence of tectonic folding on rockfall susceptibility, American Fork Canyon, Utah, USA, Nat. Hazards Earth Syst. Sci., 7, 1-14, 2007, http://www.nat-hazards-earth-syst-sci.net/7/1/2007/.

Copons, R.: Avaluació de la perillositat de caigudes de blocs a Andorra la Vella (Principat d'Andorra). Department of Geodinamycs and Geophysics, University of Barcelona, Ph.D. thesis, 244 pp., 12 plates, 2004 (in Catalan).

Copons, R.: Avaluació de la perillositat de caigudes de blocs rocosos al Solà d'Andorra la Vella, Andorra Research Institute, St. Julià de Lòria, Principality of Andorra, 214 pp., 2007 (in Catalan).

Copons, R., Vilaplana, J. M., Corominas, J., Altimir, J., and Amigó, J.: Rockfall hazard management policy in urban areas: the Andorran experience, in: Landslide Hazard and Risk, edited by: Glade, T., Anderson, M., and Crozier, M., John Wiley \& Sons Press, Chichester, 675-698, 2005.

Copons, R. and Vilaplana, J. M.: Rockfall susceptibility zoning at a large scale: From geomorphological inventory to preliminary land use planning, Eng. Geol., 102, 142-151, 2008.

Corominas, J.: The angle of reach as a mobility index for small and large landslides, Can. Geotech. J., 33, 260-271, 1996.

Corominas, J; Esgleas, J., and Baeza, C.: Risk mapping in the Pyrenees area: a case Study, in: Hidrology in mountains regions, II IAHS, 194, 425-428, 1990.

Cruden, D. M. and Varnes, D. J.: Landslide types and processes, in: Landslides. Investigation and Mitigation, edited by: Tuner, A. K. and Schuster, R. L., Special report of the Transportation Research Brand. Natural Research Council, National Academy Press, Washington DC, 36-75, 1996.

Domaas, U.: Geometrical methods of calculating rockfall range, Norwegian Geotechnical Institute, Report 585910-1, 21 pp., 1994.

Dorren, L.: A review of rockfall mechanics and modelling approaches, Prog. Phys. Geog., 27(1), 69-87, 2003.

Dussauge-Peisser, C., Helmstetter, A., Grasso, J.-R., Hantz, D., Desvarreux, P., Jeannin, M., and Giraud, A.: Probabilistic approach to rock fall hazard assessment: potential of historical data analysis, Nat. Hazards Earth Syst. Sci., 2, 15-26, 2002, http://www.nat-hazards-earth-syst-sci.net/2/15/2002/.

Evans, S. G. and Hungr, O.: The assessment of rockfall hazard at the base of talus slopes, Can. Geotech. J., 30, 620-636, 1993.

Erismann, T. and Abele, G.: Dynamics of Rockslides and Rockfalls, Springer, Berlin, 316 pp., 2001.

Fell, R., Corominas, J., Bonnard, C., Cascini, L., Leroi, E., and Savage, W.: Guidelines for landslide susceptibility, hazard and risk zoning for land use planning, Eng. Geol., 102, 85-98, 2008.

Finlay, P. J., Mostyn, G. R., and Fell, R.: Landslide risk assessment: prediction of travel distance, Can. Geotech. J., 36, 556$562,1999$. 
Goudie, A. S.: Encyclopedia of geomorphology, Routledge, 2, 1156 pp., 2004.

Guzzetti, F., Reichenbach, P., and Wieczorek, G. F.: Rockfall hazard and risk assessment in the Yosemite Valley, California, USA, Nat. Hazards Earth Syst. Sci., 3, 491-503, 2003, http://www.nat-hazards-earth-syst-sci.net/3/491/2003/.

Heim, A.: Bergsturz und Menschenleben, Beiblatt zur Vierteljahrsschrift der Naturforschenden Gesellschaft in Zurich, 77, 218 pp., 1932.

Holm, K. and Jakob, M.: Long rockfall runout, Pascua Lama, Chile, Can. Geotech. J., 46, 225-230, 2009.

Hsü, K. J.: Catastrophic debris streams generated by rockfalls, Geol. Soc. Am. Bull. 86, 129-140, 1975.

Hungr, O., Corominas, J., and Eberhardt, E.: Estimating landslide motion mechanism, travel distance and velocity, in: Landslide risk management, edited by: Hungr, O., Fell, R., Couture, R., and Eberhardt, E., Taylor \& Francis Group, London, 99-128, 2005.

Hunter, G. and Fell, R.: Travel distance angle for "rapid" landslides in constructed and natural soil slopes, Can. Geotech. J., 40, 1123-1141, 2003.

Hutchinson, J. N.: Morphological and geotechnical parameters of landslide in relation to geology and hydrogeology, in: 5th international symposium on landslides, Lausanne, edited by: Bonnard, C., A.A. Balkema, 1, 3-35, 1988.

Jaboyedoff, M. and Labiouse, V.: Preliminary assessment of rockfall hazard based on GIS data, ISRM 2003 - Technology roadmap for rock mechanics, South African Institute of Mining and Metallurgy, 1, 575-578, 2003.

Krummenacher, B. and Keusen, H. R.: Steinschlag-Sturzbahnen - Modell und Realität. Stienschlagmodellierung mit Hilfe der Computersimulationen, in: Instabilités de falaises rocheuses, chutes de blocs et ouvrages de protection, Publications de la Société Suisse de Mécanique des sols et des roches, 135, 17-23, 1997 (in German).

Legros, F.: The mobility of long-runout landslides, Eng. Geol., 63, 301-331, 2002

Lied, K.: Rockfall problems in Norway, in: Rockfall dynamics and protective work effectiveness, Instituto Sperimentale Modelli e Structture (ISMES), Bergamo, Italy, 90, 51-53, 1977.

Martin, N.: Modelling of rockfall runout range. Employing empirical and dynamical methods, Faculty of mathematics and natural sciences, University of Oslo, Ph.D. thesis, 79 pp., available at: http://www.duo.uio.no/publ/geofag/2008/82211/ Thesis34.pdf, 2008.
Meiß1, G.: Modelling the runout distances of rockfalls using a geographic information system, Zeitschrift fur Geomorpologie Supplementband, 125, 129-137, 2001.

Nicoletti, P. G. and Sorriso-Valvo, M.: Geomorphic controls of the shape and mobility of rock avalanches, Geol. Soc. Am. Bull., 103, 1365-1373, 1991.

Okura, Y., Kitahara, H., Sammori, T., and Kawanami, A.: The effects of rockfall volume on runout distance, Eng. Geol., 58, 109_ $124,2000$.

Petje, U., Ribicic, M., and Mikos, M.: Computer simulation of stone falls and rockfalls, Acta Geogr. Slov., 45(2), 93-120, 2005.

Rapp, A.: Talus slopes and mountain walls at Tempelfjorden, Spitsbergen, Norsk Polarinstitut Skrifter, 119, 1-96, 1960.

Rickenmann, D.: Empirical Relationships for Debris Flows, Nat. Hazards, 19, 47-77, 1999.

Rouiller, J. D., Jaboyedoff, M., Marro, Ch., Philippossian, F., and Mamin, M.: Pentes instables dans le Pennique valaisan, vdf Hochschulverlag AG and ETH, Zürich., Rapport final du Programme National de Recherche PNR 31/CREALP, 98, 239 pp. 1998 (in French).

Scheidegger, A. E.: On the prediction of the reach and velocity of catastrophic landslides, Rock Mech., 5, 231-236, 1973.

Shreve, R. L.: The Blackhawk landslide, Geol. Soc. Am. S., 108 pp., 1968.

Soeters, R. and van Westen, C. J.: Slope instability recognition, analysis and zonation, in: Landslides. Investigation and Mitigation, edited by: Turner, A. K. and Schuster, R. L., Transportation Research Board, National Research Council, Washington, special report 247, 129-177, 1996,

Varnes, D. J.: Slope movement types and processes, in: Landslides: analysis and control, edited by: Schuster, R. L. and Krizek, R. L., Transportation Research Board, National Research Council, Washington, special report 176, 11-33, 1978.

Vaunat, J. and Leroueil, S.: Analysis of Post-Failure Slope Movements within the Framework of Hazard and Risk Analysis, Nat Hazards, 26, 83-109, 2002.

Wieczorek, G. F., Morrissey, M. M., Iovine, G., and Godt, J.: Rock-fall hazards in the Yosemite Valley, US Geological Survey Open-file Report 98-467, 1:12000, 7 pp., available at: http://greenwood.cr.usgs.gov/pub/open-file-reports/ ofr-98-0467, 1998.

Wieczorek, G. F., Stock, G. M., Reichenbach, P., Snyder, J. B., Borchers, J. W., and Godt, J. W.: Investigation and hazard assessment of the 2003 and 2007 Staircase Falls rock falls, Yosemite National Park, California, USA, Nat. Hazards Earth Syst. Sci., 8, 421-432, 2008, http://www.nat-hazards-earth-syst-sci.net/8/421/2008/. 